\title{
Scaling of characterized slip models for plate-boundary earthquakes
}

\author{
Satoko Murotani*, Hiroe Miyake, and Kazuki Koketsu \\ Earthquake Research Institute, University of Tokyo, 1-1-1 Yayoi, Bunkyo-ku, Tokyo 113-0032, Japan
}

(Received October 22, 2007; Revised July 23, 2008; Accepted August 4, 2008; Online published October 15, 2008)

\begin{abstract}
We characterized source rupture models with heterogeneous slip of plate-boundary earthquakes in the Japan region. The slip models are inferred from strong-motion, teleseismic, geodetic, or tsunami records. For the identification of asperities in the slip models, we found that the area of subfaults retrieved with slips of $>1.5$ times the total average slip provides a size approximately equivalent to the characterized asperity by Somerville et al. (1999). We then carried out regression analyses of the size and slip for the rupture area and asperity. The obtained scaling relationship to the seismic moment indicates that rupture area $S$, average slip $D$, and combined area of asperities $S_{\mathrm{a}}$ are 1.4, 0.4, and 1.2 times larger, respectively, than those of crustal earthquakes. In contrast, the ratios of the size and slip between the asperities and rupture area $\left(S_{\mathrm{a}} / S\right.$ and $\left.D_{\mathrm{a}}^{\prime} / D\right)$ are the same for plateboundary earthquakes as for crustal earthquakes. The above analyses indicate that plate-boundary and crustal earthquakes share similar source characteristics.
\end{abstract}

Key words: Plate-boundary earthquake, asperity, source characterization, source inversion, source scaling.

\section{Introduction}

Scaling properties of heterogeneous slip distributions provide essential information on the physics of earthquake source. Recent studies have clarified systematic features of earthquake source via the scaling of slip distributions (Somerville et al., 1999; Mai and Beroza, 2000) or via slip complexity (Mai and Beroza, 2002; Lavallee and Archuleta, 2003). Waveform inversions and strong motion simulations show that asperities within the rupture area control the ground motion characteristics. Therefore, quantitative estimation of the size and slip of the asperities is important to source modeling for ground motion prediction.

Somerville et al. (1999) examined asperities inferred from long-period seismograms, collecting slip models of 15 crustal earthquakes, and estimated the size and slip for the asperities as well as rupture area. The authors then derived the scaling relationships of asperity area and total rupture area to the seismic moment. Miyakoshi (2002) added seven slip models to this dataset, including crustal earthquakes in Japan and the 1999 Izmit and 1999 Chi-Chi earthquakes. These models were in good agreement with the scaling relationship of Somerville et al. (1999).

Beresnev and Atkinson (2001a, b) examined asperities based on short-period seismograms by determining the subfault size of 25 crustal earthquakes and the 1985 Michoacan earthquake using ground motions with high-frequency recordings. Miyake et al. (2003) also used broadband ground motions to determine the strong motion generation areas of 12 crustal earthquakes in Japan using the empirical

\footnotetext{
*Now at Ministry of Education, Culture, Sports, Science and Technology, 3-2-2 Kasumigaseki, Chiyoda-ku, Tokyo 100-8959, Japan.

Copyright (c) The Society of Geomagnetism and Earth, Planetary and Space Sciences (SGEPSS); The Seismological Society of Japan; The Volcanological Society of Japan; The Geodetic Society of Japan; The Japanese Society for Planetary Sciences; TERRAPUB
}

Green's function method. The above analyses indicate that the subfault size or strong motion generation area of a moderate crustal earthquake is equivalent to the combined area of the asperities and follows a scaling law similar to that described by Somerville et al. (1999). A characterized source model that consists of rupture area and asperities works well for broadband ground motion prediction (e.g., Miyake et al., 2003); however, quantitative estimation of the size and slip of asperities is mostly limited to crustal events.

In terms of plate-boundary earthquakes, the pioneering work of Kanamori and Anderson (1975) revealed the macroscopic source scaling of the rupture area to the seismic moment. The influence of slip heterogeneities, which cannot be ignored in the prediction of strong ground motion within a subduction zone, has not yet been thoroughly investigated except by Somerville et al. (2002). Japan is surrounded by plate boundaries, and large numbers of source inversions of subduction-zone earthquakes are performed. Recent studies of plate-boundary earthquakes have reported that significant asperities have ruptured repeatedly over time (e.g., Nagai et al., 2001; Okada et al., 2003; Yamanaka and Kikuchi, 2003, 2004). This feature of the asperities may help to advance source modeling of plateboundary earthquakes.

The objective of this study is to perform source characterization of inverted heterogeneous slip models for plateboundary earthquakes in the Japan region. We estimate the source scaling and stress drop of plate-boundary and crustal earthquakes and investigate the source properties of two different classes of earthquakes.

\section{Characterizing Slip Models}

We collected published slip models of 26 plate-boundary earthquakes that occurred from 1923 to 2003 (Table 1), where the moment magnitudes range from $M_{\mathrm{w}} 6.7 \sim 8.4$. 


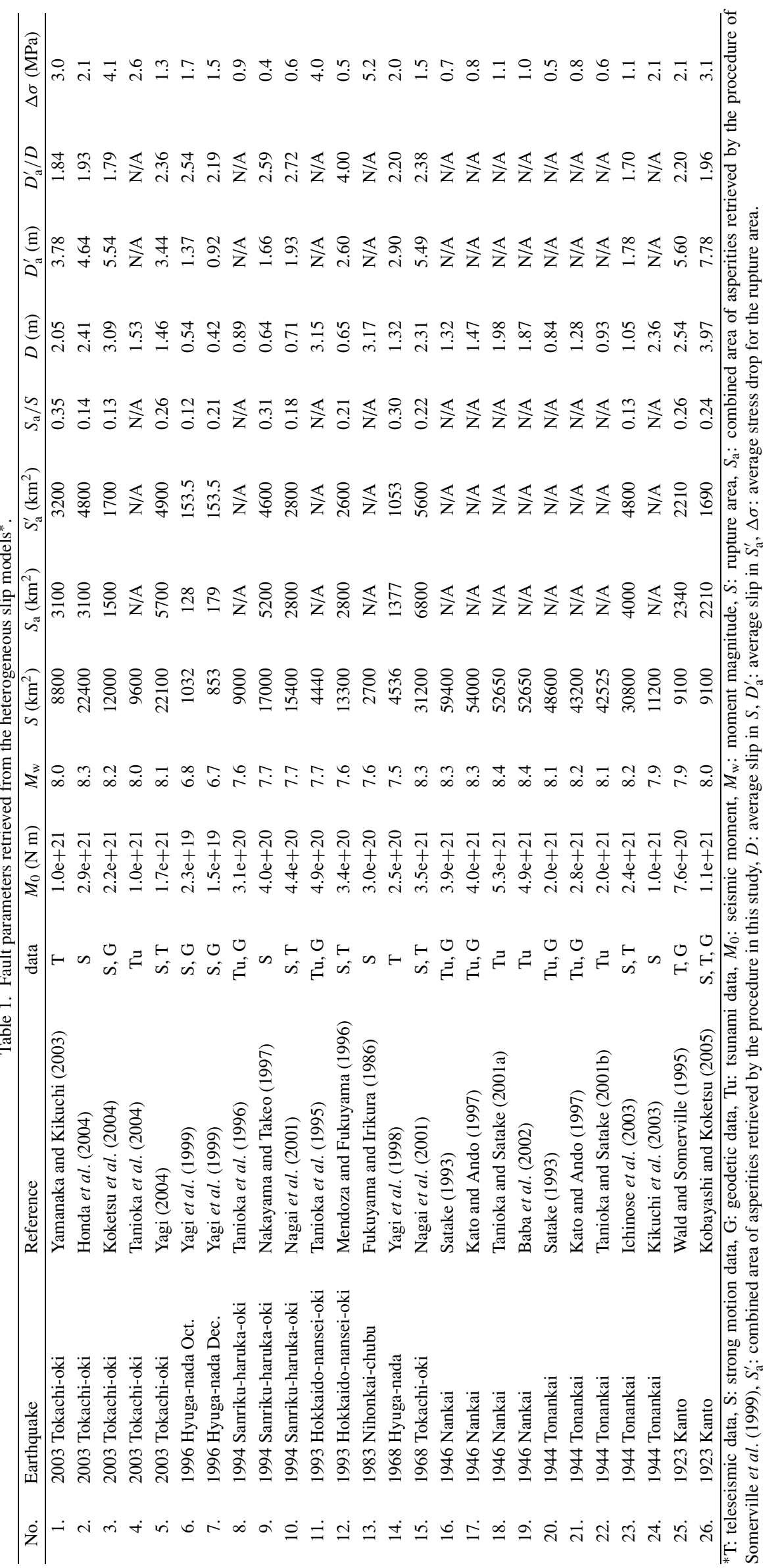



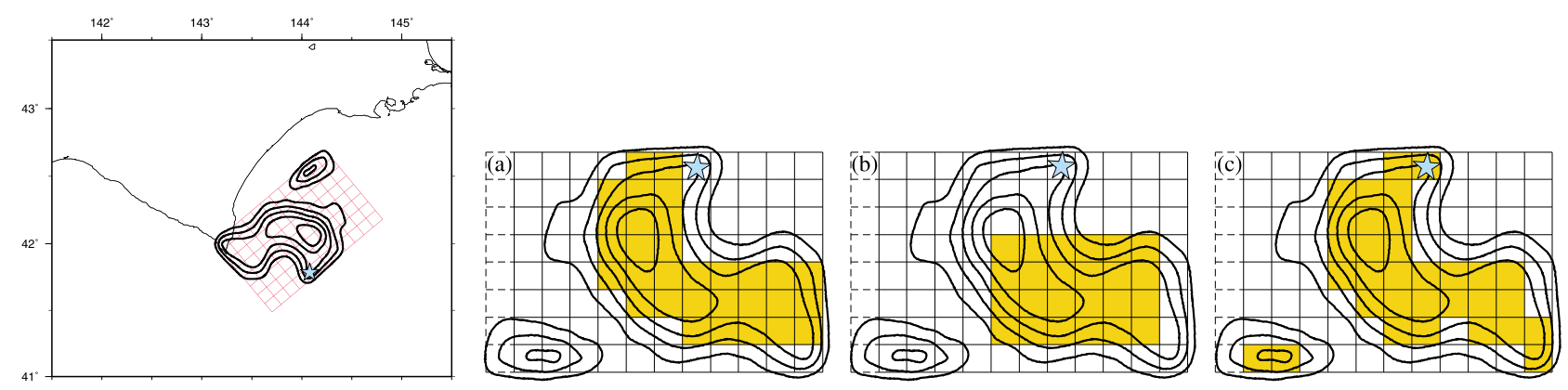

Fig. 1. Asperities (shadow zones) identified from Yamanaka and Kikuchi's (2003) slip models of the 2003 Tokachi-oki earthquake using the (a) column-wise and (b) row-wise procedures of Somerville et al. (1999). (c) is from the procedure of this study. Stars indicate hypocenters.

Slip models were constructed by waveform inversions of strong-motion or teleseismic data, or by source inversions of geodetic or tsunami data. Joint inversions are adopted to more than half of models to explain geophysical data as much as possible.

We characterized the heterogeneous slip models following the procedure of Somerville et al. (1999) and trimmed and extracted the rupture area and asperities as large slip areas. The obtained fault parameters are listed in Table 1. In some slip models, we failed to characterize asperities because of rough mesh or strong smoothing (see N/A in Table 1).

\section{Identification of Asperities}

To characterize asperities, Somerville et al. (1999) noted that "An asperity is initially defined to enclose fault elements whose slip is 1.5 or more times larger than the average slip over the fault and was subdivided if any row or column has an average slip less than 1.5 times the average slip. The asperity is then trimmed until all of the edges have an average slip equal to or larger than 1.25 times the slip averaged over the entire rupture area". However, plateboundary earthquakes are so large that they have two or more asperities in the rupture area, and the size and shape of the asperities vary significantly. For asperities of complex shape, the procedure of Somerville et al . (1999) can generate contrasting solutions depending upon whether we start with row-wise or column-wise operations. Figure 1(a) and (b) illustrates this situation for the Yamanaka and Kikuchi (2003) slip model of the 2003 Tokachi-oki earthquake. In the case of multiple solutions, we mostly make subjective selection of the best solution based on our knowledge of the earthquake. This subjective selection generally works well and produces a reasonable value for the combined area of asperities; however, resultant rectangles are sometimes a poor fit to the actual shapes of the asperities. It is even possible that subfaults composed of the largest slip are not recognized within an asperity.

To avoid such a subjective bias in the identification of asperities, we propose to retrieve subfaults with slip $>1.5$ times larger than the average slip over the entire rupture area. The results of this retrieval for the 2003 Tokachi-oki earthquake are shown in Fig. 1(c). The obtained asperity area better represents the actual shape of the zone of large slip than those in Fig. 1(a) and (b). $S_{\mathrm{a}}$ and $S_{\mathrm{a}}^{\prime}$ in Table 1 show the resultant combined area of asperities identified by
Somerville et al.'s (1999) procedure and our method, respectively. We checked the validity for recent well-recorded earthquakes (1994-2003) in Table 1. The zones of slips that are $>1.5$ times larger than the average slip occupy almost the same area as that of the rectangular asperities characterized by the procedure of Somerville et al. (1999).

\section{Source Scaling}

We carried out regression analyses of the obtained fault parameters for the plate-boundary earthquakes listed in Table 1, where the moment magnitudes range from $M_{\mathrm{w}}$ 6.7 8.4. We compared fault parameters with those for crustal earthquakes of $M_{\mathrm{w}} 5.8 \sim 7.6$ summarized by Somerville et al. (1999) and Miyakoshi (2002).

The relationship between rupture area $S\left(\mathrm{~km}^{2}\right)$ and seismic moment $M_{0}(\mathrm{~N} \mathrm{~m})$ fitting the slope $2 / 3$ is

$$
S=1.48 \times 10^{-10} M_{0}^{2 / 3},
$$

which is shown in Fig. 2(a). Comparison of Eq. (1) with the relationship provided by Somerville et al. (1999) indicates that the estimated rupture area of a plate-boundary earthquake is 1.4 times larger than that of a crustal earthquake. We next analyzed the average slip $D(\mathrm{~m})$ over the total rupture area as a function of seismic moment $M_{0}(\mathrm{~N} \mathrm{~m})$, constraining the slope to $1 / 3$ (Fig. 2(b)).

$$
D=1.48 \times 10^{-7} M_{0}^{1 / 3}
$$

Equation (2) indicates that the estimated average slip of a plate-boundary earthquake is approximately half that of the crustal earthquakes determined by Somerville et al. (1999). The greater rigidity of the plate-boundary earthquake as well as the slightly larger rupture area act to decrease the average slip.

The scaling law of combined area of asperities $S_{\mathrm{a}}\left(\mathrm{km}^{2}\right)$ to seismic moment $M_{0}(\mathrm{~N} \mathrm{~m})$ with the slope of $2 / 3$ is

$$
S_{\mathrm{a}}=2.89 \times 10^{-11} M_{0}^{2 / 3}
$$

which is shown in Fig. 2(c). The estimated combined area of asperities of a plate-boundary earthquake is 1.2 times larger than that of the crustal earthquakes determined by Somerville et al. (1999). As this factor of 1.2 is almost the same as the above factor of 1.4 for rupture area, the $S_{\mathrm{a}} / S$ of plate-boundary and crustal earthquakes-20 and $22 \%$, respectively are also similar (Fig. 2(d)). 


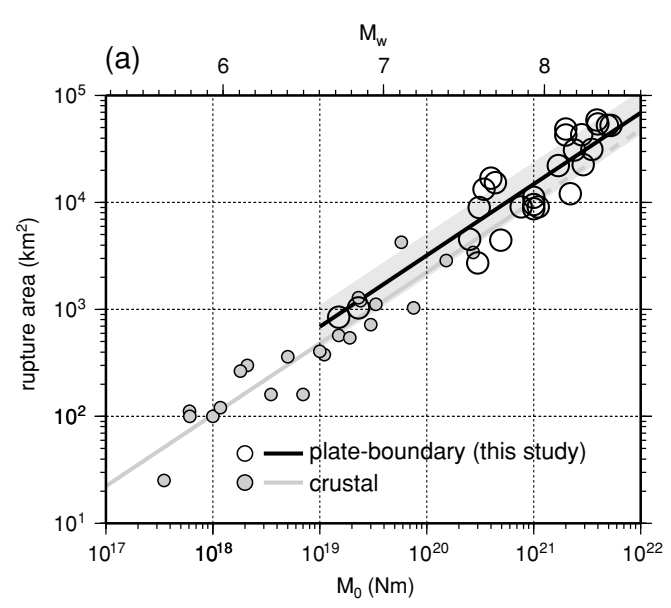

(c)

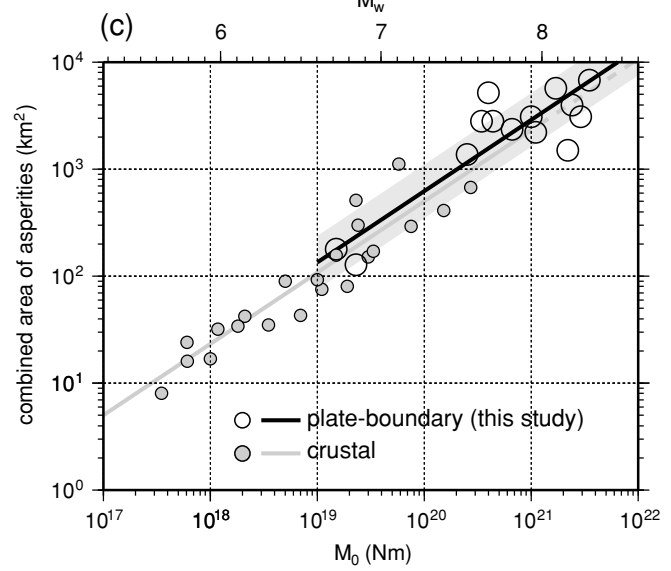

(b)

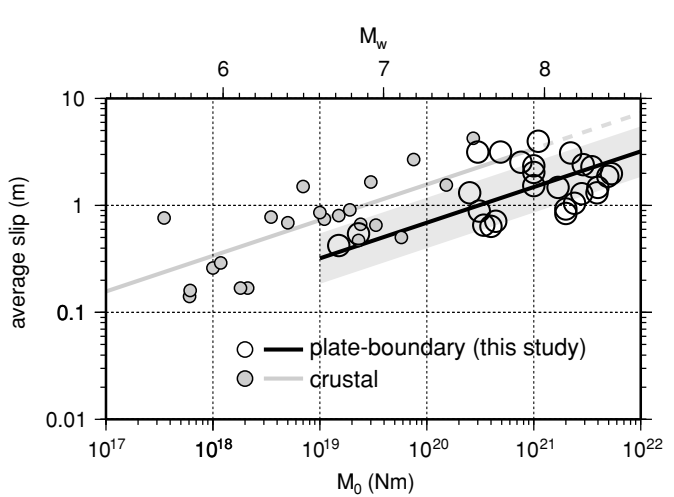

(d)

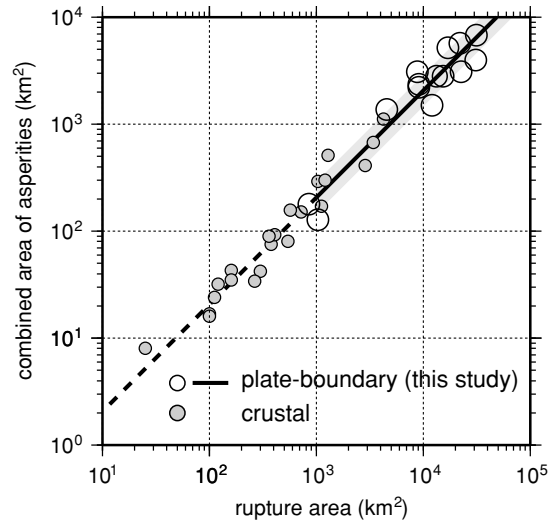

Fig. 2. Scaling relationships of (a) rupture area, (b) average slip, and (c) combined area of asperities with respect to the seismic moment. (d) Relationship between combined area of asperities and rupture area. Shadow zones indicate standard deviations of (a) 1.61, (b) 1.72, (c) 1.78, and (d) 1.41.

We then compared the average slip of asperities $D_{\mathrm{a}}^{\prime}(\mathrm{m})$ to the total average slip $D(\mathrm{~m})$. Note that $D_{\mathrm{a}}^{\prime}$ is calculated only for recent well-recorded earthquakes (1994-2003) in Table 1. This comparison yields the relationship

$$
D_{\mathrm{a}}^{\prime}=2.2 D \text {. }
$$

The factor of 2.2 derived from Eq. (4) is similar to the factor of 2.01 for crustal earthquakes determined by Somerville $e t$ al. (1999).

The scaling relationships for rupture area and average slip lead to an average stress drop $\Delta \sigma$ of $1.4 \mathrm{MPa}$, assuming a circular crack (Eshelby, 1957). This is $61 \%$ of 2.3 $\mathrm{MPa}$, which was calculated for a crustal earthquake in Somerville et al. (1999). Kanamori and Anderson (1975) and Yamanaka and Shimazaki (1990) derived $\Delta \sigma$ values of 3.0 and 4.9 MPa, respectively, from homogeneous slip models of inter-plate earthquakes. The estimated stress drops in this study are smaller than those estimated for homogeneous slip models. As homogeneous and heterogeneous slip models generally provide similar estimates of seismic moment, heterogeneous slip models in this study may have a larger rupture area that produces a smaller stress drop.

\section{Conclusions}

We collected the heterogeneous slip models of plateboundary earthquakes in the Japan region and investigated their systematic features and source scaling. As a method of identifying asperities in a slip model, we found that the retrieval of the subfaults with slip values $>1.5$ times larger than the total average slip provides a good fit for complex asperities of a plate-boundary earthquake. The obtained size of combined asperities is close to that determined using the procedure of Somerville et al. (1999).

The scaling relationships of the resultant rupture area $S$ and combined area of asperities $S_{\text {a }}$ to seismic moment indicate that $S$ and $S_{\text {a }}$ of the plate-boundary earthquakes are respectively 1.4 and 1.2 times larger than those of the crustal earthquakes, while the ratio $S_{\mathrm{a}} / S$ is similar in both studies at approximately $20 \%$. The total average slip $D$ of the plateboundary earthquakes is about a half of that of the crustal earthquakes, while the ratio of $D$ and slip averaged in asperities $D_{\mathrm{a}}^{\prime}$ is similar in both studies, at approximately two. Therefore, regarding the area of fault covered by asperities and the average asperity slip contrast, plate-boundary and crustal earthquakes share the similar source characteristics. This similarity comes from the fact that none of fault length, width, and slip values are saturated in the moment range for our dataset of plate-boundary earthquakes.

Acknowledgments. We are grateful to the authors who provided the heterogeneous slip models. We thank Martin Mai, Ken Miyakoshi, and an anonymous reviewer for improvement of this manuscript, and Kiyoshi Yomogida for editing. The compilation of the source models was supported by the Association for the Development of Earthquake Prediction. This study was supported by 
the Special Project for Earthquake Disaster Mitigation in Urban Areas from the MEXT. Figures were drawn using GMT (Wessel and Smith, 1995).

\section{References}

Baba, T., Y. Tanioka, P. R. Cummins, and K. Uhira, The slip distribution of the 1946 Nankai earthquake estimated from tsunami inversion using a new plate model, Phys. Earth Planet. Inter., 132, 59-73, 2002.

Beresnev, I. and G. Atkinson, Subevent structure of large earthquakes-A ground-motion perspective, Geophys. Res. Lett., 28, 53-56, 2001a.

Beresnev, I. and G. Atkinson, Correction to "Subevent structure of large earthquakes-A ground-motion perspective", Geophys. Res. Lett., 28, 4663, 2001b.

Eshelby, J. D., The determination of the elastic field of an ellipsoidal inclusion and related problems, Proc. Roy. Soc., A241, 376-396, 1957.

Fukuyama, E. and K. Irikura, Rupture process of the 1983 Japan Sea (Akita-Oki) earthquake using a waveform inversion method, Bull. Seismol. Soc. Am., 76, 1623-1640, 1986.

Honda, R., S. Aoi, N. Morikawa, H. Sekiguchi, T. Kunugi, and H. Fujiwara, Ground motion and rupture process of the 2003 Tokachi-oki earthquake obtained from strong motion data of K-NET and KiK-net, Earth Planets Space, 56, 317-322, 2004.

Ichinose, G. A., H. K. Thio, P. G. Somerville, T. Sato, and T. Ishii, Rupture process of the 1944 Tonankai earthquake $\left(M_{\mathrm{S}} 8.1\right)$ from the inversion of teleseismic and regional seismograms, J. Geophys. Res., 108(B10), 2497, doi:10.1029/2003JB002393, 2003.

Kanamori, H. and D. L. Anderson, Theoretical basis of some empirical relations in seismology, Bull. Seismol. Soc. Am., 65, 1073-1095, 1975.

Kato, T. and M. Ando, Source mechanism of the 1944 Tonankai and 1946 Nankaido earthquakes: Spatial heterogeneity of rise times, Geophys. Res. Lett., 24, 2055-2058, 1997.

Kikuchi, M., M. Nakamura, and K. Yoshikawa, Source rupture process of the 1944 Tonankai earthquake and the 1945 Mikawa earthquake derived from low-gain seismograms, Earth Planets Space, 55, 159-172, 2003.

Kobayashi, R. and K. Koketsu, Source process of the 1923 Kanto earthquake inferred from historical geodetic, teleseismic, and strong motion data, Earth Planets Space, 57, 261-270, 2005.

Koketsu, K., K. Hikima, S. Miyazaki, and S. Ide, Joint inversion of strong motion and geodetic data for the source process of the 2003 Tokachioki, Hokkaido, earthquake, Earth Planets Space, 56, 329-334, 2004.

Lavallee, D. and R. J. Archuleta, Stochastic modeling of slip spatial complexities for the 1979 Imperial Valley, California, earthquake, Geophys. Res. Lett., 30(5), 1245, doi:10.1029/2002GL015839, 2003.

Mai, P. M. and G. C. Beroza, Source scaling properties from finite-fault rupture models, Bull. Seismol. Soc. Am., 90, 604-615, 2000.

Mai, P. M. and G. C. Beroza, A spatial random field model to characterize complexity in earthquake slip, J. Geophys. Res., 107(B11), 2308, doi:10.1029/2001JB000588, 2002.

Mendoza, C. and E. Fukuyama, The July 12, 1993, Hokkaido NanseiOki, Japan, earthquake: Coseismic slip pattern from strong-motion and teleseismic recordings, J. Geophys. Res., 101, 791-801, 1996.

Miyake, H., T. Iwata, and K. Irikura, Source characterization for broadband ground-motion simulation: Kinematic heterogeneous source model and strong motion generation area, Bull. Seismol. Soc. Am., 93, 2531-2545, 2003.

Miyakoshi, K., Source characterization of heterogeneous source, Chikyu Monthly, Special Issue 37, 62-77, 2002 (in Japanese).

Nagai, R., M. Kikuchi, and Y. Yamanaka, Comparative study on the source processes of recurrent large earthquakes in Sanriku-oki region: the 1968 Tokachi-oki earthquake and the 1994 Sanriku-oki earthquake, Zisin, 54, 267-280, 2001 (in Japanese with English abstract).
Nakayama, W. and M. Takeo, Slip history of the 1994 Sanriku-HarukaOki, Japan, earthquake deduced from strong-motion data, Bull. Seismol. Soc. Am., 87, 918-931, 1997.

Okada, T., T. Matsuzawa, and A. Hasegawa, Comparison of source areas of M4.8 \pm 0.1 repeating earthquakes off Kamaishi, NE Japan: are asperities persistent features?, Earth Planet. Sci. Lett., 213, 361-374, 2003.

Satake, K., Depth distribution of coseismic slip along the Nankai trough, Japan, from joint inversion of geodetic and tsunami data, J. Geophys. Res., 98, 4553-4565, 1993.

Somerville, P. G., K. Irikura, R. Graves, S. Sawada, D. Wald, N. Abrahamson, Y. Iwasaki, T. Kagawa, N. Smith, and A. Kowada, Characterizing crustal earthquake slip models for the prediction of strong ground motion, Seismol. Res. Lett., 70, 59-80, 1999.

Somerville, P. G., T. Sato, T. Ishii, N. F. Collins, K. Dan, and H. Fujiwara, Characterizing heterogeneous slip models for large subduction earthquakes for strong ground motion prediction, Proc. 11th Japan Earthq. Eng. Symp., 163-166, 2002 (in Japanese with English abstract).

Tanioka, Y. and K. Satake, Coseismic slip distribution of the 1946 Nankai earthquake and aseismic slips caused by the earthquake, Earth Planets Space, 53, 235-241, 2001a.

Tanioka, Y. and K. Satake, Detailed coseismic slip distribution of the 1944 Tonankai earthquake estimated from tsunami waveforms, Geophys. Res. Lett., 28, 1075-1078, 2001 b.

Tanioka, Y., K. Satake, and L. Ruff, Total analysis of the 1993 Hokkaido nansei-oki earthquake using seismic wave, tsunami, and geodetic data, Geophys. Res. Lett., 22, 9-12, 1995.

Tanioka, Y., L. Ruff, and K. Satake, The Sanriku-oki, Japan, earthquake of December 28, $1994\left(M_{\mathrm{w}} 7.7\right)$ : Rupture of a different asperity from a previous earthquake, Geophys. Res. Lett., 23, 1465-1468, 1996.

Tanioka, Y., K. Hirata, R. Hino, and T. Kanazawa, Slip distribution of the 2003 Tokachi-oki earthquake estimated from tsunami waveform inversion, 2004, Earth Planets Space, 56, 372-376, 2004.

Wald, D. J. and P. G. Somerville, Variable-slip rupture model of the great 1923 Kanto, Japan, earthquake: Geodetic and body-waveform analysis, Bull. Seismol. Soc. Am., 85, 159-177, 1995.

Wessel, P. and W. H. F. Smith, New version of the Generic Mapping Tools released, EOS Trans. AGU, 76, 329, 1995.

Yagi, Y., Source rupture process of the 2003 Tokachi-oki earthquake determined by joint inversion of teleseismic body wave and ground motion data, Earth Planets Space, 56, 311-316, 2004.

Yagi, Y., M. Kikuchi, S. Yoshida, and Y. Yamanaka, Source process of the Hyuga-nada earthquake of April 1, 1968 ( $M_{\mathrm{JMA}}$ 7.5), and its relationship to the subsequent seismicity, Zisin, 51, 139-148, 1998 (in Japanese with English abstract).

Yagi, Y., M. Kikuchi, S. Yoshida, and T. Sagiya, Comparison of the coseismic rupture with the aftershock distribution in the Hyuga-nada earthquakes of 1996, Geophys. Res. Lett., 26, 3161-3164, 1999.

Yamanaka, Y. and K. Shimazaki, Scaling relationship between the number of aftershocks and the size of the main shock, J. Phys. Earth, 38, 305324, 1990.

Yamanaka, Y. and M. Kikuchi, Source process of the recurrent Tokachioki earthquake on September 26, 2003, inferred from teleseismic body waves, Earth Planets Space, 55, e21-e24, 2003.

Yamanaka, Y. and M. Kikuchi, Asperity map along the subduction zone in northeastern Japan inferred from regional seismic data, J. Geophys. Res., 109, B07307, doi:10.1029/2003JB002683, 2004.

S. Murotani, H. Miyake (e-mail: hiroe@eri.u-tokyo.ac.jp), and K. Koketsu 